\title{
Desenvolvimento do psiquismo e anemia falciforme: o impacto do adoecimento no exercício das atividades principais
}

\author{
Jéssica Rodrigues Rosa \\ Sueli Terezinha Ferrero Martin
}

\section{RESUMO}

A anemia falciforme é uma doença crônica que acarreta graves e numerosas implicações para a vida de seus portadores, expressas como sintomas físicos, como crises de dor, hipertensão pulmonar, síndrome torácica aguda, complicações renais e infartos silenciosos, ou outras limitações, como déficit cognitivo. Este estudo investiga as consequências da doença no exercício das atividades principais de indivíduos que dela sofrem, de acordo com seus relatos. Realizamos entrevistas semiestruturadas, utilizando o método da história de vida para coleta de dados e a identificação dos núcleos de significação para análise. Empregamos a categoria atividade, da Psicologia sócio-histórica, para subsidiar o processo de interpretação desses achados. Os resultados apontaram para grande influência do adoecimento no dia-a-dia dos sujeitos, expressa principalmente na forma de frequentes e graves rupturas do cotidiano, que afetam profundamente as possibilidades de engajamento em atividades fundamentais para seu desenvolvimento humanogenérico - em especial, atividades do brincar, de estudo e de trabalho.

Palavras-chaves: anemia falciforme; doença crônica; história de vida; psicologia sóciohistórica; saúde coletiva

\section{ABSTRACT}

\section{Psychological development and sickle cell disease: the impact of illness in the exercise of leading activities}

Sickle cell disease is a chronic blood disease that leads to numerous and serious implications to the life of its bearers, expressed as physical symptoms, like sickle cell crisis, pulmonary hypertension, acute thoracic syndrome, kidney disease and silent cerebral infarcts, or other limitations, like cognitive deficit. This study investigates the consequences of this disease in the exercise of leading activities of its sufferers, according to their reports. We conducted semi structured interviews, using the life history method for data collection, and the identification of nuclei of meanings for its analysis. We utilized the category activity, from the Social-historical psychology, to subsidize the process this data interpretation. The results evinced the major influence of illness on the subjects' everyday life, manifested mainly in the form of frequent and serious ruptures of the routine, that profoundly affect the possibility of engagement in activities necessary for their human-generic development - specially in ludic, study and work activities.

Keywords: sickle cell disease; chronic illness; life history; social-historical psychology; collective health

A anemia falciforme é considerada a doença hereditária monogênica mais comum no país e é caracterizada pela produção de uma hemoglobina anormal denominada $\mathrm{Hb} \mathrm{S}$. $\mathrm{O}$ termo "anemia falciforme" (AF) é reservado para a forma homozigótica da doença (Hb SS); indivíduos heterozigotos (Hb AS) são identificados como portadores do traço falciforme (TF) e podem levar uma vida normal. Estima-se que de 25 a 30 mil brasileiros sejam portadores de doença falciforme (Felix, Souza, \& Ribeiro, 2010).

\section{Sobre os Autores}

J.R. R. orcid.org/0000-0003-1020-7382 Hospital das Clínicas da Faculdade de Medicina de Botucatu (HCFMB) - Botucatu, $\mathrm{SP}$

jessicarrosa@gmail.com

\section{S. T. F. M.}

orcid.org/0000-0002-5874-063X Universidade Estadual Paulista Júlio de Mesquita Filho (UNESP)

- Botucatu, SP

stfm@fmb.unesp.br

\section{Direitos Autorais}

Este é um artigo de acesso aberto e pode ser reproduzido livremente, distribuído, transmitido ou modificado, por qualquer pessoa desde que usado sem fins comerciais. 0 trabalho é disponibilizado sob a licença Creative Commons CCBY-NC.

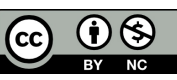




\section{-4: INTERACÃO EM LF PSICOLOGIA}

A anemia falciforme leva a significativas alterações nas propriedades físico-químicas da molécula da hemoglobina, e essas alterações, associadas a outros processos característicos da doença, estão ligadas a mecanismos que podem desencadear um amplo conjunto de sintomas, como crises álgicas, infecções, acidente vascular cerebral, hipertensão pulmonar, síndrome torácica aguda, doenças cardíacas e complicações renais (Rees, Williams, \& Gladwin, 2010), além de outras menos conhecidas, como o infarto silencioso, caracterizado pela obstrução de pequenos vasos (capilares) no cérebro. Essas condições são frequentes e recorrentes, expressando-se ao longo de toda a vida dos indivíduos.

Pelo grande número de condições neurológicas ligadas à doença falciforme, ela também tem sido associada a déficits no desenvolvimento das funções cognitivas. Entre muitos outros achados, pesquisas apontam para diminuições no escore de Quociente Intelectual (QI) de pessoas com anemia falciforme, quando comparadas a não portadoras (Schatz, Finke, Kellett, \& Kramer, 2002), e correlação entre a presença de infartos silenciosos em crianças portadoras a um desempenho mais baixo em testes neuropsicométricos (Wang, Enos, Gallagher, Thompson, Guarini, Vichinsky, Wright, Zimmerman, \& Armstrong, 2001), consequentemente, alguns estudos (como o de Epping, Myrvik, Newby, Panepinto, Brandow, \& Scott, 2013) apontam para pior desempenho escolar entre esses indivíduos.

A anemia falciforme está diretamente associada à herança de genes da raça negra. Esse dado é indicativo de que a anemia falciforme no Brasil não deve ser encarada apenas como um problema de saúde no sentido mais tradicional do termo, tendo em vista que "a desigualdade social, a discriminação e o racismo passam a ter importância na análise do quadro de saúde da população negra" (Paixão, Souzas, \& Carvano, 2004)

Embora exista cura para a doença (o transplante de células-tronco hematopoiéticas, que, entretanto, não é viável para todos os portadores), o manejo é usualmente realizado por meio de profilaxia com penicilina, imunizações, transfusões de sangue e tratamento medicamentoso.

A interrelação entre os sintomas, as perdas e limitações ocasionadas pela anemia falciforme na vida dos portadores, e as condições familiares, sociais e econômicas nas quais essses indivíduos se encontram não é simples. Ao avaliar a qualidade de vida de pessoas com doença falciforme, é necessário considerar uma série de fatores que, em sua complexa interconexão, têm impacto significativo em diferentes esferas das vidas dessas pessoas. Benton, Ifeagwu, e Smith-Whitley (2007, p.116) fazem uma síntese desse conjunto e seu impacto na adolescência:
Jéssica Rodrigues Rosa e Sueli Terezinha Ferrero Martin

Como adolescentes com doença falciforme podem ser menores do que seus colegas saudáveis nas fases iniciais da puberdade, eles podem experienciar inibição e insatisfação com sua imagem corporal. A fadiga pode reduzir sua participação em esportes, aumentando ainda mais o isolamento social e diminuindo a auto-estima. Deficits cognitivos relacionados a complicações neurológicas da doença podem ter impacto no desempenho acadêmico e competência percebida, e crises dolorosas recorrentes com a perda de dias escolares ou hospitalizações podem causar interrupções acadêmicas e sociais. A experiência destas limitações por um adolescente pode contribuir para o pessimismo, desamparo e isolamento social.

Essa condição, que persistirá e se complexificará ao longo da vida, pode ter consequências bastante sérias também para a saúde mental das pessoas com a doença, o que se traduz nos altos níveis de doenças mentais encontrados entre esta população (ver, por exemplo, Lee, Phoenix, Brown, \& Jackson, 1997).

Este artigo originou-se de parte da dissertação de mestrado da primeira autora, cujo objetivo foi investigar os aspectos que mais se destacassem no processo de desenvolvimento do psiquismo de pessoas com anemia falciforme, buscando identificar tanto suas singularidades quanto elementos universais. Dentre os achados de pesquisa, um dos aspectos que consideramos mais relevantes foi a significativa limitação dos pacientes no que se refere ao exercício de suas atividades principais - um aspecto essencial para o desenvolvimento psicológico de acordo com a abordagem sócio-histórica. Neste artigo, propusemos-nos a investigar especificamente os significados compartilhados pelos sujeitos de pesquisa a respeito dessa questão, segundo uma perspectiva materialista dialética.

Para a análise desses dados, utilizamos prioritariamente o arcabouço teórico de Leontiev (1972/1988, 1975/1984) e de Vigotski (1931/1995, 1934/1993) sobre o desenvolvimento do psiquismo. Para Leontiev (1975/1984, p. 91), embora possua uma base filogenética - "premissa completa da atividade e do reflexo psíquico" (tradução nossa) -, o aparelho psíquico constrói-se em sua complexa concreticidade a partir do exercício da atividade objetivada: a ação humana na realidade externa determina seu funcionamento interno. Leontiev (1975/1984, p. 67) afirma que "é na atividade onde se produz a transição do objeto a sua forma subjetiva, à imagem; e vice-versa, na atividade se opera também a transição da atividade a seus resultados objetivos, a seus produtos" (tradução nossa).

A categoria atividade, portanto, é tida pelo autor como fundamental para a adequada compreensão do processo de desenvolvimento do psiquismo. Entende-se atividade como o 


\section{MI* INTERACÃO EM LF PSICOLOGIA}

processo pelo qual o homem apropria-se de certas propriedades da realidade, de acordo com suas necessidades, e age no mundo, transformando sua realidade externa e interna (Leontiev, 1975/1984). Esses movimentos, de apropriação dos objetos externos ao sujeito para sua interiorização, e de objetivação, por meio do qual uma propriedade da atividade se "coisifica", permitem a incorporação de certos aspectos da realidade e sua transformação pelo homem, por meio do aparelho psíquico. 0 autor ressalta que:

Alguns tipos de atividade são os principais em um certo estágio [da vida], e são da maior importância para o desenvolvimento subsequente do indivíduo, e outros tipos são menos importantes. [...] Consequentemente, podemos dizer que cada estágio do desenvolvimento psíquico caracteriza-se por uma relação explícita entre a criança e a realidade principal naquele estágio e por um tipo preciso e dominante de atividade (Leontiev, 1972/1988, p. 63-64).

Embora Leontiev (1972/1988) cite a criança nesse trecho do texto, a atividade principal ou dominante apresenta-se em todas as fases da vida. Neste trabalho vamos enfatizar a primeira infância, em que o brincar é a atividade principal; a inserção no processo de escolarização, em que a atividade de estudo passa a ocupar esse lugar; e o trabalho, que na vida adulta passa a ser a atividade principal.

A brincadeira ensina a criança a dirigir seu comportamento não somente pela percepção imediata dos objetos, mas pelo significado dessa situação. Seu comportamento quando brinca é oposto ao seu comportamento no dia a dia, pois no brinquedo a ação está subordinada ao significado (já no cotidiano, a ação é que domina o significado). 0 brinquedo:

(...) cria uma zona de desenvolvimento proximal da criança. No brinquedo, a criança sempre se comporta além do comportamento habitual de sua idade, além de seu comportamento diário; no brinquedo é como se ela fosse maior do que é na realidade (Vigotski, 1935/1989, p. 116).

O brincar é definido, por isso, como "um estágio entre as restrições puramente situacionais da primeira infância e o pensamento adulto, que pode ser totalmente desvinculado das situações reais" (Vigotski, 1935/1989, p. 112).

Com relação à atividade de estudo, Davidov (1988, p. 158) afirma que:

(...) com a entrada na escola, a criança começa a assimilar os rudimentos das formas mais desenvolvidas da consciência social, ou seja, a ciência, a arte, a moral, o direito, os que estão ligados com a consciência e com o
Jéssica Rodrigues Rosa e Sueli Terezinha Ferrero Martin

pensamento teóricos das pessoas (tradução nossa).

Segundo o autor:

$\mathrm{Na}$ idade escolar inicial a atividade de estudo é guia e principal entre os outros tipos de atividade realizados pelas crianças. No curso da formação da atividade de estudo, nos escolares com menos idade se constitui e desenvolve uma importante neoestrutura psicológica: as bases da consciência e o pensamento teóricos e as capacidades psíquicas a eles vinculados (reflexão, análise e planificação) (Davidov, 1988, p.176, tradução nossa).

Por fim, o trabalho é identificado como atividade principal na idade adulta. Para o materialismo histórico-dialético, o trabalho é a essência do ser humano: é por meio dele que se modifica a natureza, modificando-se também a si próprio. Por possibilitar a produção dos meios de existência, o trabalho ocasiona a separação do homem em relação ao resto dos animais, pois "ao produzirem seus meios de existência, os homens produzem indiretamente sua própria vida material" (Marx \& Engels, 1931/2001, p.10-11).

O conceito de atividade principal auxiliar-nos-á, portanto, a compreender as transformações ocorridas no sistema de relações sociais dos participantes da pesquisa, na medida em que crescem e se desenvolvem, conquistando outros espaços, capacidades e responsabilidades.

Em síntese, mesmo sendo a anemia falciforme uma doença com determinação biológica, temos que considerar a unidade dialética biológico-social, pois, embora a doença seja vivenciada como problema individual, pois se expressa e afeta o dia a dia das pessoas, podendo se tornar o centro de suas vidas, é impossível abordar essa questão sem relacionála às condições sociais e históricas que a sociedade capitalista contemporânea nos coloca.

\section{MÉTODO}

A Psicologia sócio-histórica ressalta a importância de uma abordagem histórica do desenvolvimento humano, com ênfase na relação homem-sociedade e nas condições históricas concretas enquanto determinações do processo de desenvolvimento psíquico do ser humano.

Fundamentada no materialismo histórico-dialético, a psicologia sócio-histórica recorre a um conjunto de procedimentos que possibilitam a utilização desse método na Psicologia, os quais constituem a chamada análise genético-comparativa, baseada na metodologia desenvolvida por Vigotski. Esse método tem como pressupostos básicos: a análise não de um objeto, mas de um fenômeno em seu processo, estudado em seus vários momentos, que são observados em sua interrelação com o objetivo de 


\section{INTERACÃO EM LF PSICOLOGIA}

restabelecer o processo dinâmico característico da realidade; a explicação do fenômeno, e não somente sua descrição; e a investigação histórica dos comportamentos, incluindo sua gênese e processo de desenvolvimento (Vigotski, 1931/1995).

Essa perspectiva, que aponta para a existência de aspectos da realidade que não podem ser quantificados (como significados, motivos e valores), conta com formas específicas de análise dos dados, que visam a apreender as propriedades desses fenômenos. Uma delas é a categorização nos chamados núcleos de significação do discurso, assim como descritos por Aguiar e Ozella (2013), que utilizamos para a análise nesse trabalho. Esse processo inicia-se com a leitura flutuante e organização do material coletado em pré-indicadores, trechos que expressam a totalidade do sujeito e constituem uma unidade de pensamento e linguagem, segundo definição dos próprios autores, seguida da aglutinação desses em indicadores (por similaridade, complementaridade ou contraposição) e finalmente a organização desses em núcleos de significação, que "devem ser construídos de modo a sintetizar as mediações constitutivas do sujeito; mediações essas que constituem o sujeito no seu modo de pensar, sentir e agir" (Aguiar \& Ozella, 2013, p.310).

Para acessar a realidade da experiência do adoecimento na forma como foi apropriada e reproduzida pelos sujeitos pesquisados, utilizamos o método da história de vida, a partir da realização de entrevista e da observação participante. Esse método faz parte das chamadas abordagens biográficas, que se caracterizam por um compromisso com a história como "processo de rememorar", no qual a história do sujeito vai sendo revisitada por ele, com participação do pesquisador (Silva, Barros, Nogueira, \& Barros, 2007).

A pesquisa foi desenvolvida com indivíduos com anemia falciforme ( $\mathrm{Hb} \mathrm{SS}$ ) que realizam tratamento e consultas regulares no Hemocentro do Hospital das Clínicas de Botucatu (HCFMB), maior instituição pública vinculada ao Sistema Único de Saúde (SUS) da região. Optou-se pela utilização dos seguintes critérios de inclusão: ser portador de anemia falciforme (HbSS), realizar tratamento periódico no Hemocentro e ter mais de 21 de idade.

A partir da lista completa de usuários do ambulatório (52 pessoas), foram selecionados inicialmente todos que preenchiam esses critérios, totalizando 13 indivíduos. Posteriormente foi realizada nova triagem, utilizados como critérios o estado de saúde geral do indivíduo, disponibilidade para visita, e receptividade à proposta de realização da entrevista.

A população final foi composta por sete indivíduos, procedentes de diferentes cidades da região, com faixa etária entre 23 e 49 anos, sendo três do sexo masculino e quatro do sexo feminino. Os nomes utilizados para os participantes são fictícios.

Optou-se pela utilização de entrevista semiestruturada para a coleta de dados, que teve o objetivo de identificar elementos significativos no processo de constituição do psiquismo dos sujeitos, que pudessem auxiliar na compreensão desse processo. Um roteiro de entrevista, utilizado como guia durante a coleta de dados, foi formulado pelas autoras, em que dados gerais e temas como família, lazer, saúde, educação e trabalho foram abordados.

Utilizou-se também um diário de campo para o registro de fatos e informações considerados relevantes para a investigação.

$\mathrm{Na}$ primeira fase da coleta de dados, foi realizado um encontro individual com cada um dos participantes para expor a proposta de pesquisa e convidar à participação. Posteriormente, foram realizadas as entrevistas individualmente, em data e local definidos segundo a disponibilidade dos participantes. Mediante autorização, as entrevistas foram registradas em gravador portátil e, posteriormente, transcritas e analisadas. A transcrição das falas foi realizada de forma integral, mas alguns erros de concordância foram corrigidos, tendo em vista possibilitar a compreensão dos discursos.

O projeto de pesquisa foi submetido, por meio da Plataforma Brasil, ao Conselho Nacional de Saúde Comissão Nacional de Ética em Pesquisa (CONEP) - e teve sua realização autorizada (parecer $n^{\circ}$. 363.703).

\section{RESULTADOS E DISCUSSÃO}

A partir da análise dos dados, foram identificados sete núcleos de significação distintos nas falas dos participantes. Como já apontado, neste artigo daremos ênfase à análise de apenas um núcleo de significado, intitulado "O impacto do adoecimento no exercício das atividades principais", que contém o conjunto de significados atribuídos pelos sujeitos de pesquisa ao exercício das atividades principais em diferentes etapas da vida. Esse núcleo foi dividido em três subnúcleos, tendo em vista facilitar o processo de análise.

\section{O BRINCAR E AS ATIVIDADES LÚDICAS: A INFÂNCIA LIMITADA}

As repercussões da anemia falciforme no exercício das atividades principais compõem um tópico extremamente complexo na análise dos efeitos da doença sobre a vida dos portadores, por diversos motivos. Um deles é a grande variabilidade na expressão dos sintomas e efeitos da doença: 


\section{M* INTERACÃO EM LF PSICOLOGIA}

embora existam marcadores que permitam estimar sua intensidade (como, por exemplo, os níveis de Hemoglobina Fetal), cada indivíduo apresenta quadros bastante particulares, que se configuram de acordo com a interconexão de diversos fatores, muitos deles desconhecidos. Outra questão de difícil resolução é o peso e expressão de fatores socioeconômicos nesse quadro. Grande parte das pessoas com a doença (no caso deste trabalho, todos os sete participantes) pertence à raça negra ou parda população essa que, em nosso país, encontra-se marginalizada e em situação de vulnerabilidade em relação à raça branca, o que se reflete também em piores possibilidades de escolarização e formação profissional minimamente adequadas.

A análise das entrevistas permite concluir que em todos os casos estudados, a doença teve impacto significativo no exercício das atividades principais, da infância à idade adulta. Essa "marca" deixada pela doença inicia-se com o nascimento do indivíduo e se estende até o fim da vida, ocasionando dificuldades que vão se articulando a outras e criando repercussões a curto, médio e longo prazo.

Todos os participantes identificaram limitações significativas durante a infância ocasionadas pela doença. Em alguns casos - como os de Roberto, Nelson e Cecília -, esses limites eram associados mais a eventos agudos (internações ocasionais) ou a limitações que não impossibilitavam completamente as brincadeiras (cansaço durante jogos mais fatigantes, como pega-pega ou futebol). É o que Nelson classifica de uma infância "até que normal":

vivia até que... normal vamos dizer assim. Lógico que com as limitações que eu tinha. Uma criança normal podia, vamos supor, brincar o dia inteiro. Eu tinha que ir intercalando [...] eu queria brincar, não podia, ficava já meio chateado, hoje eu já... entendo.

Outra participante, Cora, afirma que brincou muito pouco quando pequena, ao contrário das irmãs: "elas brincaram mais, foram mais peraltas [risos]. Eu já não [...] eu não ficava quase em casa, né? [...] Por causa do problema, eu ficava mais no hospital [...] foi assim uma boa parte da minha vida".

Para além do sofrimento com essas limitações, às quais as pessoas com a doença se acostumaram ao longo dos anos, alguns participantes fazem relatos de episódios de gravíssimo adoecimento já na infância. Roberto, por exemplo, relata:

Eu lembro que... fiquei um, eu perdi um ano de escola, que... [...] fui internado aqui, aí por falta de tratamento eu... quase vim a óbito, né, que... porque aqui eles não queriam me transferir pra lá, aí meu pai não tinha como me levar pra lá, naquela época. [...] eu fiquei seis meses internado

\section{Jéssica Rodrigues Rosa e Sueli Terezinha Ferrero Martin}

[com a voz falhando]. E perdi um ano de escola, fiquei seis meses lá.

Maria relata que "não sabia nem o que era brincar, porque nós não tivemos infância pra brincar". Ela estudou apenas até os 12 anos de idade; depois, começou a trabalhar como empregada doméstica para ajudar a sustentar a família (embora bem antes dessa idade já ajudasse a família cuidando dos irmãos mais novos e fazendo tarefas de casa). Por isso, conta que era "muito difícil brincar. Os outros [irmãos] brincaram, eu já não brinquei”.

O relato de Mário (irmão de Maria) apresenta as consequências da anemia falciforme de uma forma extremamente concreta:

A única coisa que eu lembro é que eu vivia no hospital, e até agora eu tô no hospital. Nunca parei, nunca vivi dentro de casa, só dentro de hospital [...] Não cheguei ter essa infância de brincar. [questionado sobre o motivo] É porque eu só vivia internado!

Em todos os casos, os participantes identificaram algum grau de comprometimento da vivência da infância ocasionado pela doença. De forma mais generalizada, isso é percebido na forma de restrições: quando, por exemplo, a criança se cansava mais do que seus pares em um jogo e precisava parar de brincar. Por vezes, o cansaço vinha acompanhado de dor ou outra forma de mal-estar - dados que são confirmados pela literatura, tendo em vista que existem diversos fatores que tendem a limitar a prática de exercício nesses indivíduos, como a reduzida capacidade de transporte de oxigênio, adaptações cardíacas resultantes da anemia crônica, alterações pulmonares resultantes de episódios frequentes de síndrome torácica aguda ou dano ao sistema vascular periférico relacionado à ocorrência de oclusão microvascular (Castro et al., 1994).

Crises álgicas, cujos episódios duram normalmente de quatro a seis dias, mas podem persistir por semanas (Ministério da Saúde - Secretaria de Atenção à Saúde, 2006), também aparecem nos relatos como elementos limitantes na prática de brincadeiras.

A impossibilidade de que a criança com doença falciforme esteja tão envolvida com atividades do brincar como outras crianças traz inegáveis consequências no que se refere ao processo de desenvolvimento do psiquismo. As brincadeiras são as atividades principais do indivíduo durante a infância; Vigotski já apontava que as situações desencadeadas pelos jogos possibilitam o desenvolvimento da vontade, da capacidade de fazer escolhas conscientes (Vigotski, 1935/1989).

O engajamento nessas situações, e seu consequente resultado para o desenvolvimento, é frequentemente negados 


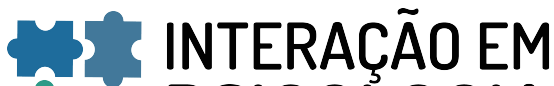 ET PSICOLOGIA}

às pessoas com a doença falciforme ao longo da infância, de diversas formas, como pudemos verificar pelos relatos de vários participantes da pesquisa. Por vezes não estão em condições de participar dos jogos propostos pelos colegas, principalmente devido à dor ou a limitações físicas, e muitas vezes passam longos períodos de tempo apartados dos colegas (como quando estão hospitalizados). Hospitalizações, exames e consultas têm grande impacto nas possibilidades de engajamento da criança nas atividades principais - tendo em vista que, de forma geral, essas intercorrências consomem parte significativa do tempo que a criança passa com seus pares (e mesmo com outros adultos, como professores) intensificando o contato com o círculo familiar.

\section{AS ATIVIDADES DE ESTUDO: ESCOLARIZAÇÃO FRAGMENTADA}

Todos os participantes de nossa pesquisa, em maior ou menor medida, identificaram que a anemia falciforme teve impacto ao longo do processo de escolarização.

Cora explica que frequentemente tinha que abandonar as aulas para ir ao hospital, e que "era difícil porque... eu ia, sentia as crises, tinha que voltar [...] a escola é uma coisa assim, você tem que manter frequência".

Maria fala sobre como o trabalho na infância dificultava seus estudos:

[...] depois eu tive que sair da escola também pra trabalhar, né. [...] Nós num brincamos. Porque com 12 anos que a gente vinha pra cá eu tava na escola, né, até os 12 eu tava na escola, aí depois nós nos mudamos pra cá, aí eu já tive que... cuidar de família, mesmo. Eu tive que lavar, passar, cozinhar... e cuidar dos meus irmãos, eu num tive infância.

Assim como ela, Cecília, Mário e Roberto começaram a trabalhar ainda na infância. Retomando o conceito de atividade principal, podemos perceber nesses casos um choque entre dois tipos de atividade: a de estudo, identificada como a atividade principal desse período do desenvolvimento, e a de trabalho, imposta a esses indivíduos pela família (mas respondendo, em última instância, a uma necessidade econômico-social). Nesses casos, a atividade principal concorre e, em alguns casos, é suplantada por outras formas de atividade - no caso, o trabalho, atividade principal da idade adulta. Não apenas muitos desses indivíduos não tiveram plenas condições de brincar e de estudar como, em alguns casos, foram coagidos por suas condições de existência a aprender e se engajar em formas de atividade que ainda não tinham capacidades físicas e psicológicas de realizar adequadamente. É importante lembrar o papel que a atividade de estudar tem no desenvolvimento humano, conforme apresentado anteriormente (Davidov, 1988).

Os sintomas da doença parecem ter afetado de forma significativa as atividades de estudo. Cecília afirma que "sentia bastante dor" quando estudava no período noturno, o que ela associa às temperaturas mais baixas. Cora afirma que seus professores a ajudavam a compensar as faltas com trabalhos extracurriculares, para que ela não repetisse de ano. Roberto também afirma que "tinha bastante falta, né, por questão de... de ficar internado, né. Quase repeti por falta, tive que compensar por trabalhos". Para Maria, a doença "influenciou sim [os estudos], eu acho que influenciou, porque senão eu tinha estudado até mais... até mais pra frente, né?".

Nelson conta que o impacto da anemia falciforme sobre seu processo de escolarização se deu desde a pré-escola, e continuou ao longo do tempo:

Teve época de eu ficar internado lá... quase um ano, seguido [...] eu tinha que... estudar mais, se debater mais pra mim tá... à mesma altura deles, então, aí, todo dia. Então sempre foi uma coisa assim... meio pesada pra... pra mim. Ali na, na Pediatria não sei se você sabe, ali eles têm uma escolinha, ali. Então ia dando uma ajuda.

Mário discorre sobre outras formas pelas quais a doença influenciou suas atividades escolares:

Ah, já sofri pela doença, né? [...] Chamavam eu de anêmico... vivia doente. [...] Ah, eu chorava, chorava, de raiva. Pra num fazer umas... machucar eles, que estavam me xingando, eu sentava e chorava. Que a minha raiva era pegar eles, e bater, bater...

Esse trecho da entrevista de Mário remete mais uma vez a quão complexa é a interação das múltiplas determinações na esfera motivacional da vida da pessoa com anemia falciforme. Frequentemente nos deparamos com perspectivas que "compartimentalizam" os efeitos da doença na vida do indivíduo doente - as ocorrências de dor como eventos isolados, o "déficit cognitivo" como uma outra consequência da doença - como se coexistissem paralelamente e independentemente um do outro, sem interação. Retomando Leontiev (1975/1984, p.178), lembramos que o "Eu" "não está no indivíduo, não está debaixo da superfície de sua pele, mas em sua existência".

A forma como a anemia falciforme afeta as funções cognitivas das pessoas é um dos tópicos mais extensamente pesquisados atualmente. Como já apontamos anteriormente, a doença está associada a diversas possíveis complicações neurológicas.

Alguns estudos, entretanto, destacam o importante papel 


\section{W'INTERACÃO EM ET PSICOLOGIA}

do ambiente social e das condições de vida no desenvolvimento dessas condições. Brown et al. (1993), por exemplo, compararam o processamento cognitivo e funcionamento acadêmico de crianças com a doença ao de irmãos sem ela, controlando variáveis como idade, status socioeconômico e gênero. Embora tenham identificado desempenho inferior entre os portadores da doença em alguns dos testes, os autores apontam que "a maioria das medidas estava, entretanto, relacionada à classe social, sugerindo que há variabilidade no funcionamento cognitivo de jovens nos quais a doença falciforme tenha sido diagnosticada que pode, em parte, ser atribuída à classe social" (Brown et al., 1993, s/p).

Como consequência, muitos dos portadores apresentaram dificuldades escolares e de colocação no mercado de trabalho. Um estudo de 1985 identificou maior percentual de pessoas com a doença desempregadas e menor percentual com ensino médio completo, além de menor renda pessoal média entre essa população (Farber, Koshy, \& Kinney, 1985).

Os achados desta pesquisa levam-nos a concluir que as alterações cognitivas associadas à anemia falciforme não podem ser explicadas apenas pela somatória de complicações neurológicas características da doença. Como já dito anteriormente, a anemia falciforme expressa-se clinicamente das mais diferentes maneiras, com maior ou menor gravidade, em diferentes indivíduos. A análise do impacto da doença para as funções cognitivas deve, portanto, também englobar essa diversidade, levando à consideração do indivíduo em sua integralidade, complexidade e com as particularidades de sua história de vida. Quando temos, como visto anteriormente, uma gama gigantesca de possíveis sintomas e sequelas da doença e uma população que já está sujeita a certas limitações em suas possibilidades concretas de existência, é apenas de forma dialética que poderemos compreender de fato o impacto desses fatores na vida daqueles que estão sujeitos a eles.

\section{O PROCESSO DE FORMACÃO E EXERĊ́CIO PROFISSIONAL: TRABALHO E EXPLORAÇÃO COMO DÁDIVAS}

Quando analisamos os relatos de experiência profissional dos participantes, percebemos um conjunto de "carências cumulativas": as limitações, restrições e dificuldades expostas anteriormente se manifestam com brutalidade no cotidiano de trabalho, culminando em dificuldades de colocação profissional, frequentes trocas de emprego, afastamentos, demissões e aposentadoria precoce.

Roberto demonstra ter muita clareza sobre o impacto do adoecimento em suas

\section{possibilidades de escolha e exercício profissional:}

[A doença] me atrapalhou bastante na área profissional [...] às vezes eu conseguia um serviço que o patrão entendia, e às vezes um serviço em que o patrão não entendia. Eu trabalhava ali três meses... me mandava embora. Conseguia um serviço. Trabalhava três meses... me mandava embora.

Ele acrescenta que é difícil encontrar chefias que sejam compreensivas em relação às restrições impostas pela doença, que o mantenha trabalhando e o pague adequadamente quando ele adoece e precisa ficar "de dez a quinze, a vinte dias internado".

Mário conta que ao longo da vida trabalhou, ao todo, por cerca de "seis, sete anos". Ele afirma ter vivido alguns períodos de melhora no estado de saúde que possibilitaram sua colocação no mercado de trabalho:

[...] daí eu comecei um pouco mais a arrumar [trabalho], tal, daí num vivia muito, tão no hospital, tal... assim, mas daí de repente, pum, de novo. De repente começa a fazer tudo de novo [...] Começa a dar crises de anemia, tal, tal, tudo de novo, aí correr atrás tudo de novo [...] Eu tive uma melhora durante cinco anos, depois já caiu tudo de novo. Entendeu?

Cora conta que em seus dois primeiros empregos, em fábricas de tecidos, o trabalho pesado desencadeava crises de dor frequentemente. Ela trabalhou por seis e sete meses ininterruptos, até que a intensidade das crises a levou a pedir demissão.

Remetendo mais uma vez ao conceito de atividade principal, identificamos o trabalho como a principal atividade na idade adulta, aquela ao redor da qual se organizam as demais atividades do indivíduo. 0 trabalho enquanto atividade principal diferencia-se de outras formas de atividade por uma característica fundamental: ele gera valor. A força de trabalho - única mercadoria capaz de produzir um valor maior que o dela própria - é moeda de troca de todo trabalhador: a partir dela, o trabalhador recebe um salário, que é transformado em objetos necessários à sua sobrevivência.

Entretanto, o trabalho não é igual para todos, e nem toda forma de trabalho possibilita ao sujeito o desenvolvimento pleno de suas funções psicológicas e uma existência livre e saudável. Marx e Engels (1931/2001) consideravam a divisão do trabalho uma das forças capitais da história: à classe dominante cabe o trabalho intelectual, que dispensa a utilização de força física e se dá em condições que permitem o desenvolvimento de funções psicológicas mais elaboradas, como as formas mais refinadas de pensamento abstrato. Às classes subjugadas, nem sempre resta a possibilidade de 


\section{W'INTERACÃO EM ET PSICOLOGIA}

escolha do tipo de trabalho a ser realizado; são sempre aos indivíduos pertencentes a ela que cabem formas de trabalho rejeitadas pelas elites, formas de trabalho mais cruéis, perigosas, marginais, que geram grande desgaste físico e sofrimento para o trabalhador. No caso dos participantes desta pesquisa, praticamente todos se inserem nesse grupo, tendo, portanto, a classe social a que pertencem como determinação fundamental no seu processo saúde-doença, além da origem étnica que pode intensificar as desigualdades sociais.

Quando crianças, viram-se diante de diversas limitações que interferiram em seu desenvolvimento físico, psicológico e intelectual. Passaram à adolescência ainda buscando superar essas limitações, e se viram diante de novas dificuldades durante o período de escolarização. Muitas vezes incapazes de completar até mesmo o Ensino Médio, pouco restou a eles exceto empregar-se onde foi possível, e trabalhar na medida do suportável.

Sobre a demissão de seu último emprego, Mário afırma:

Por causa de... doença, por causa disso, e daí mandaram eu embora [...] Ninguém pega, em lugar nenhum [...] que nem, nesse serviço que eu faço, eu sou bom... entendeu? Costura [...] ganhava dois mil reais. Tava bom. Mas só que eu tava com esses cortes na barriga. Trabalhei durante um mês, fui passar pela [empresa de convênio de saúde], já mandaram eu embora.

Não é incomum que por falta de qualificação profissional adequada e pelas dificuldades em ser contratado, a pessoa com anemia falciforme tenha de se empregar em locais que demandem esforço físico vigoroso. Cora conta que trabalhou numa tecelagem quando jovem, um trabalho "pesado né, eu tinha muito sangramento pelo nariz [...] o esforço demais causa hemorragia". Roberto conta que trabalhou numa fábrica de pães de alho, onde seu trabalho exigia que passasse, constantemente, de uma câmara fria para um forno:

[...] quente, frio, quente, frio, quente, frio... [...] 0 dia todo. 0 dia todo. 0 dia todo. Então aí ó, teve muita crise quando eu trabalhei nessa fábrica. Aí foi onde eu saí. Eu vi que não ia dar pra mim.

Às vezes os sintomas geram tentativas extremas de controlá-los, para evitar faltas:

Nossa, teve um dia eu tive uma, uma crise e... e eu não que, eu não queria, eu tinha medo de faltar... de ser mandada embora, porque eu precisava de um emprego. Então eu fui tomando dipirona, tomando dipirona sem controle, de repente, apaguei! [...] eu falava "meu Deus, fazia 15 dias que eu não tinha faltado, se faltasse de novo, ia..." medo de perder o serviço, né (Cora).
A pessoa com doença falciforme, muitas vezes, se vê compelida a "fazer mais" do que seus colegas de forma a "compensar" por aquilo que ela identifica como limitações individuais. 0 sujeito que precisa superar inúmeras limitações desde seu nascimento para realizar mesmo atividades mais cotidianas com frequência chega à idade adulta responsabilizando-se por características e condições que são encaradas em separado do contexto social, econômico em que se expressam. 0 problema passa a ser não conseguir trabalhar tanto ou tão rápido quanto os outros - e não o fato de a pessoa com doença falciforme estar sujeita a condições que dificultem seu acesso à saúde, lazer e educação (e os impactos disso em sua vida a longo prazo), ou o fato de ela não ter sua condição adequadamente reconhecida pelo poder público como, em muitos casos, impeditiva de certas formas de trabalho.

Algumas pessoas com anemia falciforme conseguem obter afastamento, auxílio-doença ou aposentadoria por invalidez; outros optam por pedir demissão e/ou mudar de trabalho quando os sintomas se tornam tão intensos que impossibilitam sua continuidade; outros ainda mantêm-se no trabalho até que surgem complicações tão sérias que não resta outra opção ao indivíduo a não ser parar de trabalhar. As dificuldades financeiras e para obtenção de emprego são apontadas como as principais causas do aparecimento de estados depressivos em portadores da doença adultos (Damlouji, Kevess-Cohen, Charache, Georgopoulos, \& Folstein, 1985).

Para além de todas as dificuldades que foram expostas até o momento, não podemos perder de vista que a prevalência da anemia falciforme é maior entre a população afrodescendente, que foi e ainda é historicamente discriminada das mais diversas formas.

\section{Segundo Campante, Crespo, e Leite (2004, s/p):}

[...] podemos dividir a concretização do salário de um indivíduo em três etapas: formação, inserção e definição salarial. As evidências mostradas acima sugerem que em todas estas etapas os negros estariam sendo prejudicados. Primeiro, porque em média são menos escolarizados, tendo uma formação pior. Em seguida, existem evidências de discriminação na sua inserção. Por fim, suas características são remuneradas de forma diferenciada [...].

Apesar de todas essas determinações, e possivelmente por conta dos inúmeros desafios e dificuldades envolvidos no processo de colocação profissional, das condições adversas a serem enfrentadas para a manutenção de um emprego, e das características negativas de algumas das próprias atividades profissionais, o trabalho mantém para a maior parte dos participantes uma dimensão mais positiva que 


\section{WIIITERACÃO EM ET. PSICOLOGIA}

negativa. Roberto anseia por se fazer útil, trabalhando quase neuroticamente a despeito de possuir cada vez menos tempo para a família - o que parece associado a um sentimento de dívida para com seu empregador. No relato de Cora, é evidente um sentimento de "gratidão" a alguns de seus empregadores, que "deram uma chance" para que trabalhasse; e sua irmã, Cecília, embora com melhores condições de saúde, também se refere ao trabalho como um prêmio, algo que foi conquistado. Maria, que trabalhou desde pequena apesar da doença, relaciona o trabalho a um aprendizado, um saldo positivo na vida - conquistado com muito esforço por conta da doença; e seu irmão, Mário, lastima não ter conseguido manter-se empregado apesar de suas habilidades no trabalho realizado. Apesar de membros do mesmo núcleo familiar e expostos ao mesmo ambiente durante a infância e parte da juventude, Maria e Mário têm histórias de vida muito diferentes: Maria foi capaz de trabalhar, tornar-se relativamente independente e criar uma família, enquanto Mário trabalhou pouco, com a maioria dos contatos sociais restritos aos moradores da casa onde mora.

Apesar das qualidades eminentemente positivas associadas ao trabalho pelos participantes, é importante apontar que ele ainda se caracteriza como um processo de assujeitamento dos indivíduos, determinado pelos interesses do capital, e não pelo atendimento às necessidades e interesses humanos. Para Marx (1844/2004), o trabalho é fundamento ontológico do ser social, no entanto, na sociedade capitalista contemporânea, converte-se em meio de subsistência. Como apontado pelos participantes, além das determinações gerais e condições de trabalho que se colocam para toda a classe trabalhadora, no caso deles é, também, superação de limites e, simultaneamente, imposição deles, quando intensifica os sintomas da doença e os impossibilita de trabalhar; motivo de orgulho e de vergonha, considerando-se as demissões que as pessoas vivenciam com frequência por "falta de produtividade"; símbolo de liberdade e de aprisionamento.

\section{CONSIDERAÇÕES FINAIS}

Neste artigo, buscamos identificar se e de que maneira as consequências da anemia falciforme e outras determinações às quais as pessoas com a doença estão sujeitas influenciaram a realização das atividades principais ao longo de suas vidas, partindo de seus próprios relatos e dos conjuntos de significados associados, de acordo com eles, a essa questão. Identificamos que essa população está sujeita a um conjunto de forças que, muitas vezes, impossibilitam, limitam ou modificam suas possibilidades de agir e interagir com o ambiente e as outras pessoas. Os sintomas da doença e o contato com os hospitais e serviços de saúde atravessam a infância de muitos dos participantes, impedindo ou restringindo suas possibilidades de se engajar em jogos e outras atividades do brincar. Desde cedo surge para a criança a consciência a respeito dessas limitações e sua reação a isso é determinada não apenas por sua forma particular de entender e lidar com a situação, mas com as reações de seus pais, amigos e familiares.

As atividades de estudo, mais tarde, acontecem num espaço e tempo no qual hospitalizações, crises de dor, consultas frequentes ao médico, anemia e cansaço são ocorrências comuns. A criança acostuma-se a essas condições, mas isso não significa que deixem de interferir em sua vida de alguma forma. Os estudos apontando dificuldades de aprendizado e alta taxa de abandono escolar entre as pessoas com anemia falciforme indicam que, muitas vezes, elas não são capazes de dar conta das exigências que Ihe são impostas pela escola, família e sociedade, e o estudo, atividade principal desse momento da vida, é negligenciado, posto de lado pelos que não conseguem se engajar adequadamente em seu exercício, ou compete com outros tipos de atividade (como, por exemplo, o trabalho).

Finalmente, a idade adulta muitas vezes exige da pessoa com doença falciforme a realização de atividades de trabalho incompatíveis ou mesmo danosas a sua condição. Submetido, frequentemente, a uma infância limitada e uma escolarização que não respondeu a suas necessidades, não é incomum que a pessoa com anemia falciforme se veja sem condições de escolher um tipo de trabalho mais adequado a suas características. Muitas vezes, a própria possibilidade de inserir-se no mercado de trabalho é algo a ser conquistado, tendo em vista que o desemprego e as demissões são ocorrências comuns nesse grupo (seja porque não consegue manter-se empregado, seja devido à influência da doença na produtividade). Àqueles que não veem outra possibilidade senão afastar-se do trabalho, resta uma outra longa batalha: tentar obter benefício da seguridade social em um país sem políticas voltadas a essa população, para que possa continuar sobrevivendo.

Consideramos esses achados de grande relevância para o estudo da anemia falciforme, pois lançam luz sobre as consequências físicas, sociais, psicológicas e econômicas do adoecimento na vida dos portadores, e no desenvolvimento de suas atividades lúdicas, de estudo e trabalho, que consideramos essenciais para o desenvolvimento psíquico de todo ser humano. Esperamos que estes dados reforcem a importância da elaboração de novos estudos relacionados às condições de vida e desenvolvimento de portadores de anemia falciforme e da elaboração de políticas públicas voltadas a essa população. 


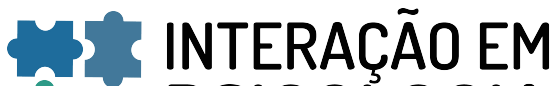 PSICOLOGIA}

\section{CONTRIBUIÇÃO DE CADA AUTOR}

J.R.R. foi responsável pela pesquisa de campo, análise do material coletado, revisão e redação do artigo; S.T.F.M. colaborou na análise e discussão dos dados, revisão e redação do artigo.

\section{DECLARAÇÃO DE CONFLITOS DE INTERESSES}

Os autores declaram que não há conflitos de interesse no presente artigo.

\section{DECLARAÇÃO DE FINANCIAMENTO}

A pesquisa relatada no manuscrito foi financiada parcialmente pela bolsa de mestrado da primeira autora (CAPES).

\section{REFERÊNCIAS}

Aguiar, W. J., \& Ozella, S. (2013). Apreensão dos sentidos: aprimorando a proposta dos núcleos de significação. Revista Brasileira de Estudos Pedagógicos, 94(236), 299322. doi: 10.1590/S2176-66812013000100015

Benton, T. D., Ifeagwu, J. A., \& Smith-Whitley, K. (2007). Anxiety and depression in children and adolescents with sickle cell disease. Current Psychiatry Reports, 9(2), 172, 114-121. doi: 10.1007/s11920-007-0080-0

Ministério da Saúde - Secretaria de Atenção à Saúde. (2006). Manual de condutas básicas na doença falciforme. Brasília: Ministério da Saúde.

Brown, R. T., Buchannan, I., Doepke, K., Eckman, J. R., Baldwin, K., Goonan, B., \& Schoenherr, S. (1993). Cognitive and academic functioning in children with sickle-cell disease. Journal of Clinical Child Psychology, 22, 207-218. doi: 10.1207/s15374424jccp2202_7

Campante, F. R., Crespo, A. R. V., \& Leite, P. G. P. G. (2004) Desigualdade salarial entre raças no mercado de trabalho urbano brasileiro: aspectos regionais. Revista Brasileira de Economia, 58(2), 185-210. doi: 10.1590/S003471402004000200003

Castro, O., Brambilla, D.J., Thorington, B., Reindorf, C. A., Scott, R.B., Gillette, P., Vera, J. C., \& Levy, P.C. (1994). The acute chest syndrome in sickle cell disease: incidence and risk factors. The cooperative study of sickle cell disease. Blood, 84(2), 643-649.

Damlouji, N. F., Kevess-Cohen, R., Charache, S., Georgopoulos, A., \& Folstein, M. F. (1982) Social disability and psychiatric morbidity in sickle cell anemia and diabetes patients. Psychosomatics, 23(9), 925-931. doi: 10.1016/S00333182(82)73062-2
Davidov, V. (1988). La ensenãnça escolar y el desarrollo psíquico. Moscu: Progresso.

Epping, A. S., Myrvik, M. P., Newby, R. F., Panepinto, J. A., Brandow, A. M., \& Scott, J. P. (2013). Academic attainment findings in children with sickle cell disease. Journal of School Health, 83(8), 548-553. doi: 10.1111/josh.12064

Farber, M. D., Koshy, M., \& Kinney, T. R. (1985). Cooperative study of sickle cell disease: demographic and socioeconomic characteristics of patients and families with sickle cell disease. Journal of Chronic Diseases, 38(6), 495-505.

Felix, A. A., Souza, H. M., \& Ribeiro, S. F. (2010). Aspectos epidemiológicos e sociais da doença falciforme. Revista Brasileira de Hematologia e Hemoterapia, 32(3), 203-8. doi: 10.1590/S1516-84842010005000072

Lee, E. J., Phoenix, D., Brown, W., \& Jackson, B. S. (1997). A comparison study of children with sickle cell disease and their non-diseased siblings on hopelessness, depression and perceived competence. Journal of Advanced Nursing, 25(1), 79-86. doi: 10.1046/j.1365-2648.1997.1997025079

Leontiev, A. N. (1984). Actividad, conciencia y personalidad. México: Editorial Cartago.

Leontiev, A. N. (1988). Uma contribuição à teoria do desenvolvimento da psique infantil. In Vigotski, L. S., Luria, A. R., \& Leontiev, A.N. Linguagem, desenvolvimento e aprendizagem. São Paulo: Ícone/Editora da Universidade de São Paulo.

Marx, K. (2004). Manuscritos econômicos-filosóficos. Trad. Jesus Ranieri. São Paulo: Boitempo Editorial.

Marx, K., \& Engels, F. (2001). A ideologia alemã. São Paulo: Martins Fontes.

Paixão, M., Souzas, R., \& Carvano, L. M. (2004). A arte do encontro: levantamento das fontes de dados sobre as desigualdades raciais no Brasil. Rio de Janeiro: Observatório Afrobrasileiro.

Rees, D. C., Williams, T. N., \& Gladwin, M. T. (2010). Sickle-cell disease. Lancet, 376(9757), 2018-2031. doi: 10.1016/ S0140-6736(10)61029-X

Schatz, J., Finke, R. L., Kellett, J. M., \& Kramer, J. H. (2002). Cognitive functioning in children with sickle cell disease: a meta-analysis. Journal of Pediatric Psychology, 27(8), 739748. doi: 10.1093/jpepsy/27.8.739

Silva, A. P., Barros, C. R., Nogueira, M. G, \& Barros, V. A. (2007). Conte-me a sua história: reflexões sobre o método de história de vida. Mosaico, 1(1), 25-35.

Vigotski, L. S. (1989). A formação social da mente. São Paulo: Martins Fontes.

Vigotski, L.S. (1993) Obras Escogidas: Tomo II. Madri: Visor e MEC. 


\section{N"INTERACÃO EM \\ ET. PSICOLOGIA}

Vigotski, L. S. (1995). Obras Escogidas: Tomo III. Madri: Visor e MEC.

Recebido em: 27/12/2017

Wang, W., Enos, L., Gallagher, D., Thompson, R., Guarini, L., Vichinsky, E., Wright, E., Zimmerman, R., \& Armstrong, F. D. (2001). Neuropsychologic performance in school-aged children with sickle cell disease: a report from the cooperative study of sickle cell disease. Journal of Pediatrics, 139(3), 391-397. doi: 10.1067/mpd. 2001.116935 